\title{
The Role of Innovation on Start-Up Failure vs. Its Success
}

\author{
Munira Aminova* \\ Vrije Universiteit Brussel, Vesalius College, \\ Brussels, Belgium. \\ E-mail: munira.aminova@gmail.com \\ Edoardo Marchi \\ Vrije Universiteit Brussel, Vesalius College, \\ Brussels, Belgium. \\ E-mail: edoardomarchi22@gmail.com
}

Received November, 2020; Accepted January, 2021

\begin{abstract}
It is evidenced that approximately $90 \%$ of startups businesses fail. This paper investigates key variables that affect startups performance and contribute to their survival. The impact of innovative strategies such as new products, new markets, new ideas, and patents is thoroughly analyzed. The paper uses the database of ZEW with 60.000 observations for 7 years (2007-2016). The study uses quantitative research methods. The results show that innovation is positively correlated to startups' performance. Variables such as investment, industry, start-up size, founder's education, and employees' educational level have affected startups' innovations and have contributed to improving their performance. On the other hand, there was no correlation between start-ups' incubators and performance.
\end{abstract}

Keywords: Startups; Innovation; Entrepreneurship

Type: Research paper

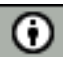

BY This work is licensed under a Creative Commons Attribution 4.0 International License.

DOI: 10.51325/ijbeg.v4i1.60

\section{Introduction}

There are very few startups that achieve a status of unicorn-startups. This is possible largely by identifying new opportunities which differentiate them, and getting strong competitive advantages through innovation in a niche market. Yet, 9 out of 10 start-ups fail (Patel, 2019); the reasons for the failure include but not limited to: bad management, lack of funds, lack of market need, lack of experience, strong competition, and more (Krishna, Agrawal \& Choudhary, 2016). Looking at US market (2018), only 40 of the companies reached the status of unicorn start-ups.

The definition of 'start-up' has been studied in many disciplines and defined from different perspectives (Baregheh, Rowley \& Sambrook, 2009). Forbes (2013) defines 'start-up' as a company working to solve a problem where the solution is not obvious and success is not guaranteed. Other definitions state that startup is a company that is built on extreme uncertainty, has at its core innovation to create products and services which they wish to revolutionize the market' (Moroni, Arruda \& Araujo, 2015).

Literature reviews reveals that innovativeness has a positive correlation in increasing firms' market power, by increasing its competitive advantage or reducing costs consequently increasing the possibilities for these start-ups to enhance performance and 
the likelihood of survival (Hyytien, Pajarien \& Rouvinen, 2015; Aljamal ,2018 ,Mohamed HessianAlareeni, 2019 ,2018,). On the other hand, this strategy can lead the business down a riskier path with much more fiscal instability, thus exposing it to higher chances of failure. Empirical literature states that start-ups face low survival rate in their first years of existence in a market, but the further they go, the lower it gets (Hyytien, Pajarien \& Rouvinen, 2015; Alareeni, 2018; Afana, and EL Agha, 2019; Al-Afifi, 2019; Salman, and Battour, 2020).

The literature does not give a clear cut answer in regards to the survival rate of startups vs. their innovativeness, as well as no clear positive or a negative correlation of startup innovativeness vs. its performance. The purpose of this paper is to test the effects of innovation output measured with different variables to performance (survival or otherwise) of start-ups in Germany. The research will try to find an answer the following question: To what extent does innovation affect starts up performance and limit their failure? Although there are studies that have explored the effect of innovation on the survival rate of start-ups, they do not go into depth with the impact on the performance. The research methodology adopted is outlined and the findings follow. The data analysis will be conducted using quantitative research methods. The data derives from a dataset from Zentrum für Europäische Wirtschaftsforschung (ZEW), also known as Leibniz Centre for European Economic Research. ZEW is a German data panel which collects data from start-ups in Germany from 2008 to 2017. Finally, the paper will conclude with the main concepts and the takeaways of innovation, followed by limitations and suggestions for future studies.

\section{Literature Review}

Innovation is as an idea, practice or object that is perceived as new by the entity adopting it. (Jalonen, 2012). It is a tool to enhance firms market power, improve the ability to deal with competition, reduce product costs, improve dynamic capabilities, and lead to enhance absorptive capacity (Hyytien, Pajarien \& Rouvinen, 2015). Innovation can be new products and services, new process technology, new organizational structure or administrative systems, or new plans or program pertaining to organization members (Baregheh, Rowlay \& Sambrook, 2009).

All of these processes or ways to differentiate and innovate, give access to perceive changes either as a response to changes in the external environment or as a pre-emptive action to influence the environment itself (Baregheh, Rowlay \& Sambrook, 2009). And have different gradation depending on the organization's resources, capabilities strategies and requirements. (Baregheh, Rowlay \& Sambrook, 2009).

Furthermore, innovation can be the key for small and big businesses survival, as it is recognized as having a central role of creating value and sustaining competitive advantage (Baregheh, Rowlay \& Sambrook, 2009), by distinguishing the factors that deliver superior value and taking advantage of them rather than focusing on all the factors the industry 
competes on (Kim \& Mauborgne, 1997). Therefore, battling competitors over targeted segmentation of the market, makes the competitors irrelevant through the strategic logic of value innovation (Kim \& Mauborgne, 1997). An example of this concept is Apple, as it has proved that innovation can go beyond just product, service or technological innovation, but innovation is delivering value by reinventing key elements of a business, which make it difficult for competitors to execute and imitate (Lingardt et al., 2009).

Hyytinen, Pajarinen \& Rouvinen (2014) gathered, data from Finnish start-ups and found evidence that innovativeness has a positive relationship with the likelihood of survival by enhancing market power, reducing costs, and allowing the creation of dynamic capabilities and absorptive capacities. Thus, small firms that are successfully able to peruse innovation as a core business strategy can lead to an increase in productivity, growth potential, and likelihood of survival. (Gujarro, Garcia \& Van Auken, 2009).

If companies fail to innovate, jobs and profit will suffer and our standard of living will suffer (UK Department of Trade, 2003). iIn order to sustain competitive position and to straighten it, organizations and economies must incorporate innovation (Baregheh, Rowley \& Sambrook, 2009).

Highly skilled employees: Employees with the higher education diploma are perceived as a component of innovation and a driver for economic growth and innovation worth investing (Freel, 1999). As better skilled work force, all other things being equal, is likely to be a more innovative workforce (Freel, 1999).

Universities, as being the provider for this human and intellectual capital (Freel, 1999), play an important role in the innovation ecosystem (Leten, Landoni \& Van Looy, 2014). They educate the future graduates and supply skilled workers in the fields that are essential for corporate $R \& D$, and conduct scientific research by generating knowledge that can be contribute for new or existing economic activity (Cohen, Nelson \& Walsh, 2000).

Observations about this idea has been made through policy initiatives. An example is the initiative undertaken by the European Commission in 2011, to modernize the education system, emphasizing an increase in the number of graduates and strengthening the links between education, research, and businesses to further promote innovation in the continent (Leten, Landoni \& Van Looy, 2014).

Many other countries have been inspired by the importance of university research for industrial innovation, and have therefore created policies to stimulate this knowledge outputs. For example, is the US enacted the Bayh-Dole Act, which aims in the financial support of joint research project of university and firms (Link \& Siegel, 2005).

Several studies have reported a positive correlation of both education and scientific research on the technological performance of firms, as a result displaying benefits from the presence of scientific work and graduates (Leten, Landoni \& Van Looy, 2014). A similar finding was by Van Looy, Landini, Callaert, et al. (2011), which revealed the same 
positive relationship between the scientific productivity of universities and their entrepreneurial effectiveness.

Startup size: Many scholars have studied and discussed the effect of firm size as a factor that has impacting innovation. This can be traced back to the work of Schumpeter (1942); he claims that large firms are more innovative than small firms due to the higher incentive to spend on R\&D. Many researchers argue that a larger organizational size enables innovation (Damanpour, 1992), as bigger firms have the ability to more diverse facilities that can support different types of innovation. Additionally, they have the ability to employ a larger R\&D staff, which leads to economies of scale for R\&D (Stock, Greis \& Fischer, 2001). The possibility to employ more skilled workers, will increase the possibility to recognize more unforeseen innovations (Kamier \& Schwartz, 1982) and can gather greater resources to be able to have technical knowledge and capabilities. (Damanpour, 1992). On the other hand, there are arguments stating that larger does not necessarily mean more innovative (Huge, 1980). Rather, some smaller firms are more innovative, as they are more flexible, they have greater ability to adapt and improve, therefore greater means for innovation (Damanpour, 1992). Another advantage is the possibility to avoid the "bureaucratic inertia" and the greater ability to adapt to the market changes (Stock, Greis \& Fischer, 2001).

Furthermore, there are studies expressing that the relationship between the size and innovation relies on the market characteristics. Larger firms have greater innovation in imperfect competition where it is more capital-intensive, concentrated, and advertisingintensive. Whereas, small firms have an innovative advantage where total innovation and skilled workers play an important role, in early life-cycle industries where it's predominantly close to the competitive model and large firms comprise a high share of the market (Acs \& Audretsch, 1987).

Industry: Industries with greater levels of R\&D intensity are home to higher rates of firm level innovation, as it is more common when industry dynamisms are high (Thornhill, 2005). A study by Kirner, Kinkel \& Jeager (2008) classifies the manufacturing industry in 3 parts: the low-tech, medium-tech and the high-tech sectors, and these are divided by their respective average shares of expenditure in $R \& D$. Low tech sectors are typically dominated by food, paper, textiles, rubber and basic metal products, high-tech are comprised of medical, optical instruments, chemical industry and etc.

Another study shows that the selection classification in low-tech, medium-tech and hightech industries does not reflect the reality as not all the firms belong to their industry classification if we look at the individual R\&D intensity. (Kirner, Kinkel \& Jeager, 2008) Nevertheless, the study further concludes that low tech in the product and service industry are not performing well compared to the high tech and medium-tech.

Alternative literature by Wagner (2008) conducted a study in German transportation industry measured the innovation as the amount of successful complete innovation 
projects brought to the market. The study concluded that on average $60 \%$ is the manufacturing industry are innovators, $52 \%$ of the firms from the knowledge intensive industry are innovators and $35 \%$ of innovators were in the other services. It is explained that this differentiation in innovation from sector to sector on the nature of successful innovation in the different competitive environments (Thornhill, 2006). For example, if we take the high-tech industry, new products that apply new technologies are constantly emerging to differentiate from the competition, thus there is a constant of a high magnitude and pace in the industry. On the other hand, other sectors, such as the food industry, might not require the same newness to be able to succeed (Thornhill, 2006).

Investments: Financial resources can be one of the biggest barriers to innovation (Guijarro, Garcia \& Van Auken, 2009), as the risk of monitoring costs and the difficulty of assessing the innovation, make the challenge of financing innovation even more difficult (Freel, 2000). There are many conflicts between the need of investing and the risk associated with the increasing transaction costs and debts mostly subject to small firms because of their limited financial resources, which might prevent firms from investing in innovation (Guijarro, Garcia \& Van Auken, 2009). There is, however, a historical linkage between financial market activity to radical innovation in manufacturing, communication and transportation going back to the mid-1700s (Nanda, Rhodes-Kropf, 2013). Though financing radical innovation requires more than just capital. It requires a mindset of experimentation and ability to accept failure (Nanda, Rhodes-Kropf, 2013).

Investments for small firms are essential for successful innovation, notably during the early product development stages where much of the costs are in R\&D. As Wood (1997) finds, firms reporting substantial innovative output have a higher proportion of staff who are technically skilled, thus investments permit small firms to be able to attract more graduates for their innovative process, and are able also to further investments in assets that can bring to more successful innovations.

Small Businesses undergo different ways of financing themselves. The majority of empirical work documents the important role that financial intermediates \& financial markets may play in the rate of innovation in start-ups (Kerr \& Nanda, 2015). Further, the effect of venture capital investments in start-ups as they are led to greater patents rates, since they suggest that VC investors have an impact thru their role of monitoring, financing and board representative. (Kerr \& Nanda, 2015). The existence of supporting entrepreneurial and startup ecosystem is another factor positively affecting innovativeness of companies (Aminova M., et al, 2020).

Nanda \& Rhodes-Kropf's (2013) study finds that start-ups that were founded in more active periods, filed more patents in their years subsequent to their foundation thus there is a correlation between financial investment cycles and innovation cycles, that we probably will have to take into account. Furthermore, investment may impact the technological development and its innovations, by financing promising ideas and thus shaping the nature of R\&D (Kerr \& Nanda, 2015). 
Founders qualifications: Many reports argue that managers and founders have an important role in the process of innovation. Their knowledge and decision making induces the creation of new product and services which ultimately highlighting the firm's performance and growth, which can be a decisive factor between success and failure (Casson, 2005). Literature further expresses that educational level of an individual is considered to be very important for the post-entry performance in terms of productivity, profitability and growth (Ganotakis, 2010).

Keollinger, on the other hand, questioned this theory, stating that knowledge and expertise can be a 'double-edged' sword. Meaning that entrepreneurs with very high levels of education $\&$ experience, believe that these attributes are sufficient to guide successful ventures. This way of thinking prevents them to interact with other sources which could lead to identifying changing business opportunities, thus even leading to failure of their businesses due to market changes.

A study by Lynskey further claims that even if in theory people with higher education are expected to perform better than those without it, he believes that those with PhDs may possibly not perform as well, implying that there is a $U$ shaped relationship between the variables of education and performance. Education is also a dynamic asset (Aminova \& Jegers, 2011); continuous learning and education are more important than the single static university degree.

Start-up centers, as they are defined in the start-up panel, are formed in the majority by business incubator and accelerators. These businesses are based on programs that have the task to help entrepreneurs and their start-ups convey their ideas, technologies and products into their markets in the most successful way possible. These entities proved a variety of support services. These programs are directed by experienced businesspersons who focus on coaching and development by providing start-ups with advice, business services, financing, and office space to help the development and the launch into the markets (Bollingtoft and et. al., 2005).

It is widely accepted that incubators or accelerators are highly effective as they offer recruitment and retention of entrepreneurial businesses. They support job creation efforts and promote the creation of fiscal revenues. In addition, they provide access to scientific, technical, and professional experts that inform and guide entrepreneurs in the creation of intellectual property-that is further developed into marketable products, technologies, and services. (Eshun, 2004). Hence, creating a higher chance for small start-ups to survive as they get prepared to face any challenge, they might encounter in their business life cycle.

As some study suggests, it can be difficult to determine whether the start-up would have succeeded with or without the assistance of the incubator, and this is the basis for many arguments against incubation (Bearse, 1998., Reynolds, 1999). 
Thus, in contrast to the belief that the effectiveness of survival rate and success these entities provide, policy analyst of Kauffman foundation claims that there is some positive bias assessment due to misuse of measurement and data, to have a positive result in the industries (Konczal, 2012). He argues these results with several statistical problems that he faced such as missing or inaccurate data, limited population and sample size measures may have heavily skewed the results.

\section{Hypotheses}

The following hypothesis are put forward in this paper based on the above literature review: Startup size, investment, the industry dynamics, education/academic qualifications of the founders and other employees, startup centers (incubators, accelerators), startup innovativeness (measured by the number of patents) have either positive or negative impact of startup performance.

Graph 1: The conceptual framework

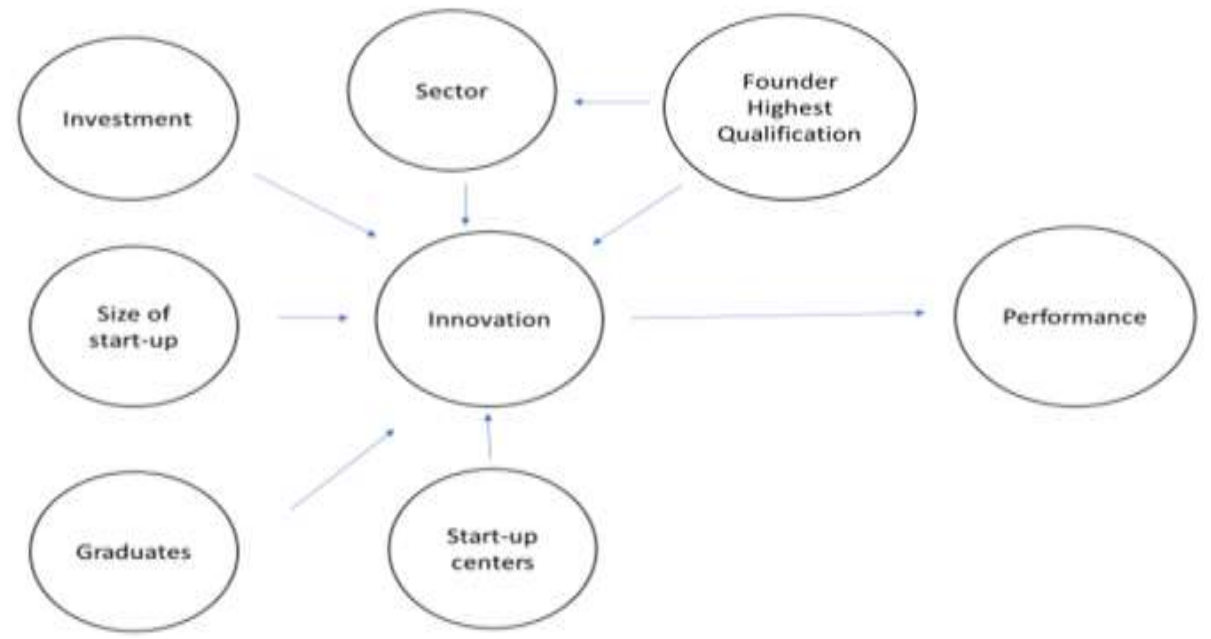

The detailed hypothesis of this paper are:

(H1): the low innovativeness of a start-up has a negative impact on its performance. This statement, based on the study by Baregheh, Rowlay \& Sambrook (2009), assumes that innovation is a big incentive to create competitive advantage thus resulting in a higher performance.

(H2): investments have a direct positive influence on innovation, thus inducing a positive performance.

(H3): the industry in which the startup operates has either a positive and a negative influence on innovation, depending on industry's competitive environment, thus the relative innovativeness of a firm in the industry is a determinant of its performance. The following hypothesis was formulated based on the following two researches: Huge, (1980) \& Stock, Greis \& Fischer, (2001).

(H4): Start-up size has a positive influence on the start-up innovativeness. This statement assumes that the bigger the firms is the more innovative it can be.

(H5): the start-up that 1) have the founders with academic qualification and 2) have a high percentage of graduated employees are more likely than other start-ups to 1) 
innovate and 2) perform better. The statement based on Cohen, Nelson \& Walsh (2000) and Ganotakis (2010) assumes that the higher the qualification the founder has and the higher the number of graduates the company hires the greater the chances are that it will innovate and ultimately perform better.

(H6): founders' highest qualification that corresponds to the sector/industry of his/her business has a positive correlation to innovativeness of the star-tup. This statement assumes that the more the qualification is corresponding to the sector of the business, the higher the possibility of the start-up to innovate and have a positive performance in return. (H7): start-up that used support services of start-up centers have a higher innovativeness and performance than other start-ups. This states that start-ups centers can have a positive influence on the start-up innovativeness process and consequently on its performance.

\section{Research Design \\ Methodology}

Data collection: The data source is the data collected a German data panel of ZEW. It was done with respect to the cross-sectional dimension of the population in Germany, thus the institute created respectively a questionnaire that was carried out by using computer-aided telephone interviews. This format had a duration of 25 minutes that acquired a very detailed quantitative collection of data. As the population is different each year, the center has decided on dividing the questionnaire into two parts. The first questionnaire is done specifically for new participants introduced into the population for the first time. It aims to collect specific information and characteristics of the firm according to 18 topics (See table 2 below). Furthermore, each topic has different questions formulated covering a list of specific variables necessary to create a detailed data profile of the company.

Table 2: Firm characteristics by ZEW research

1. General information about the enterprise
2. Founder/founder team
3. Start-up from scientist and academic spinoff foundations
4. Employment and labor demand
5. Entrepreneurial orientation
6. Enterprise type, product characteristics, innovation
7. Development of enterprise: success, expenses and revenues
8. Use of social media
9. Internationalization
10. Public support and main bank relationship
11. Financing and capital investment
12. Other financing source
13. Management teams
14. Business objectives
15. Composition of the founding team- Woman and man
16. Corporate spinoff
17. Supplier credits and factoring
18. Leasing


The second questionnaire is done for the firms which have already participated in the previous years. The second questionnaire focuses on changes within the participating firm over time with the same format of topics and questions. The topics handled by the panel include sensitive characteristics and variables for both company and individuals, which could harm the participants' businesses by potentially sharing information to the competitors. Therefore, ZEW anonymizes the data, thus assuring that firms can only get re-identified with disproportional high effort of time, money and manpower.

The method executed by the panel to obtain the information is via computer-aided telephone directly with the participant, thus assuring the confidentiality needed for such detailed and sensitive topics.

The advantages that related to using such a data set are: (1) is inexpensive, fast and an easy way to approach the data, (2) the researcher can gain deep insight to specific answers as the panel has a lot of data, (3) is ideal as it give the possibility to reach on a large number of participants spread over the country which normally would take a research many months to be able to reach and interview, (4) it assures anonymity, thus avoids the research to get into any legal dispute.

The limitations of using such a data are: (1) the data come only from Germany population thus it is not fully representative of the entire start-up population in the world, (2) that questionnaire just looks at answers they designed thus does not give the freedom of exploring new variables, (3) the population is stratified thus has some limitations on being fully random and unbiased.

\section{Data analysis}

The data allows us to test our hypotheses. The main model that was used to be retain a clear answer is:

$$
\mathrm{yi}=\beta_{0}+\beta 1 \mathrm{xi}+\epsilon_{\mathrm{i}}
$$

Where: $\mathrm{Y}$ are dependent variables $=$ (investments, sector, size, graduated employees and founder's highest qualification); and the $\mathrm{x}$ is the independent variables = (innovation, performance, investments, performance, startup centers); $\epsilon$ is known as the random error it something that is not observable and not estimable. $\beta_{0}$ and $\beta_{1}$ are the regression coefficients thus unknowns. To be more exact $\beta_{0}$ is also called intercept; while $\beta_{1}$ is called slope indicating the change of $\mathrm{Y}$ on average when $\mathrm{X}$ increases one unit.

Furthermore, to test the hypothesis we will be using the following formula:

$$
t=\frac{x-\mu}{\sqrt{s^{2} / n}}
$$

where $\mathrm{x}$ bar is the sample mean, $\mathrm{s}^{2}$ is the sample variance, $\mathrm{n}$ is the sample size, $\mu$ is the specified population mean and $t$ is a $t$ quantile with $n-1$ degrees of freedom. 
This will give us the possibility to result its significant two-tail $\mathrm{p}$-value $(\mathrm{P}>\mathrm{t})$, which will determine if the we can reject or accept the Null Hypothesis $H_{0}$.

As we can see from the formula, it can be clearly identified that the main variables that have been explained throughout the paper are key components of our hypothesis. This will lead to a further understanding of why start-ups fail and how entrepreneurs can reduce start-up failure.

\section{Selection of concept}

The data is collected are from German Start-ups, specifically those that have operated between 2008 and 2016. As our target population is not confined by sector or any other specific criteria, we have at our disposal, thanks to the panel, a very large population size of about 6,000 startups for each year. Thus, our aim is to analyze the data for all the startups from 2008 to 2016, which is a convincing representative sample size of the entire startup population in Germany. Receiving the data from such a prominent institutional database will assure to minimize the chance of error, consequently allowing to further assure a successful data analysis.

\section{Operationalization of concept}

The four independent variables (i.e. graduates, founders' knowledge, size of start-up, industry), with the one middle variable (i.e. investments and innovation), and the dependent variable (i.e. performance). For the purpose of this paper, a further definition of the variables and a specification of how they are being measured is presented below.

1. Innovation is defined as the idea of producing new products, services, and technologies to enhance market power. For the purposes of this paper innovation will be measured is through the following scale: 0 as not having produced any new product or patents, and 1 it has brought a new product or patents. In the data panel these two variables were created.

2. Graduated employees refer as the number of employees that have graduated from a university which have been hired by the start-ups.

3. Investments refers as an amount of monetary resource that the firm is using to invest into itself to conduct its function of producing a product or service. Three types of financial resources are distinguished: revenue generated from sales, founders' own means (such as personal savings used for firm start-up), and capital from external third-party providers.

4. Size of startup refers as the number of employees that the company has employed each year to be able to produce a product or a service in a market.

5. Industry/sector refers as the market that the company is currently operating in which is offering or selling a product or a service. Below is the classification and data collection of ZEW based on industries. 
Table 2: Different sectors recorded in the data set

\begin{tabular}{|ll|}
\hline \multicolumn{1}{|c|}{ high technology industries } \\
\hline 1. & cutting-edge technology manufacturing \\
2. & high-technology manufacturing \\
3. & technology-intensive services \\
4. & software supply and consultancy \\
\hline & non-high-tech industries \\
\hline 5. & non-high-tech manufacturing \\
6. & skill-intensive services (non-technical consulting services) \\
7. & other business-oriented services \\
8. & consumer-oriented services \\
9. & construction \\
10. & wholesale and retail trade (without trade agents) \\
\hline
\end{tabular}

6. Performance refers as a positive monetary outcome which will be represented as the revenue per employee, computed as the revenue earned from the start-up divided by its employees between 2008 to 2016, the choice of using such a criterion is to be able to have a fair and uniform measure between all the start-up of any size.

7. Founder highest qualification refers to the founders' levels of qualification that he/she has acquired during the academic or during his professional life. The scale of qualification is measured as followed: 0 the founder has acquired no degree, 1 the founder has received a qualification as apprenticeship/ professional school, 2 the founder has been qualified as master craftsman or has attended a vocational college, 3 he/she has acquired a qualification from a college or university.

Table 3: Qualifications of the founders

\begin{tabular}{|l|l|}
\hline \multicolumn{1}{|c|}{ Profession $\mathbf{1}$ or $\mathbf{2}$} & \multicolumn{1}{c|}{ Field of study $\mathbf{3}$} \\
\hline Mercantile professions & Economic/ business science \\
Technical professions & Natural sciences (including medical science) \\
Social professions & Mathematics/ computer science \\
Hotel and restaurant industry & Engineering sciences \\
Other professions & Other fields of study \\
& \\
\hline
\end{tabular}

8. Start-up center refers to programs that help start-up in the initial business lifecycle by providing technical and knowledge-based support. 


\section{Results}

The results will be discussed and analyzed in two parts. Firstly, the interpretation of the key outcomes of each variable will be presented to have a better overview of the data will be discussed. This will be followed by a detailed analysis and discussion of regression outputs of each tested variable and finish with the resulting statistical and economical significance of each result.

\section{Descriptive Statistics}

Table 4: descriptive statistics

\begin{tabular}{|l|c|l|l|r|r|c|}
\hline \multicolumn{1}{|c|}{ Variable } & Codes & \multicolumn{1}{c|}{ Obs } & \multicolumn{1}{c|}{ Mean } & Std. Dev. & Min & Max \\
\hline Patents & anzpat4 & 63,866 & 0.06 & 0.238 & 0 & 1 \\
\hline New products & mneu2 & 63,866 & 0.11 & 0.314 & 0 & 1 \\
\hline Size & Voll & 56,822 & 1.85 & 5.9 & 0 & $3.00 \mathrm{E}+07$ \\
\hline Performance & ums & 53,049 & 342935.9 & 882971. & 0 & 1 \\
\hline Start-up center & grunenderzentr & 2,303 & 0.62 & 0.241 & 0 & $5.00 \mathrm{E}+07$ \\
\hline Investment & inv & 59,535 & 38756.08 & 336388. & 0 & 29 \\
\hline Graduates & bes_h & 35,440 & 1.35 & 3.145 & 0.914 & 3 \\
\hline $\begin{array}{l}\text { Founder } \\
\text { qualification }\end{array}$ & abschluss & 63,646 & 2.11 & & 0 & 0 \\
\hline
\end{tabular}

Table 4 represents the descriptive statistics of all the variables used in this study. Summarized commands on the Strata program were used to acquire the results of important features which will be used to analyze the data. The main focus is on the result to measure the mean used to better evaluate the result that we have obtained, thus acting as a benchmark of the entire sample.

The variables: patents a code (anzpat4) was created to represent the following: if throwout the years the start-up replied at least ones that it had one patent, it would be registered for all the years as 1 . However, if the start-up never had replied to the questioner or has stated to not have any patents, it would have been taken as a 0 for all the years it has been in the sample. For the new product variable, the case is different, if the start-up replied on that he/she had a new product regional/national/worldwide, we would count as 1 . If the start-up simply said no than it would count as 0 .

Furthermore, as portrayed in Table 4, we can see that we have various numbers of observations. This is due to start-ups being given the choice not answer to the question if they feel that it is not appropriate. Nevertheless, we still believe that this will not have any major negative impact on the results as there is a very large number of observations within all the variables. Moreover, the variable of start-up centers only have 2,303 observations as it has been an added variable since 2016. Thus, we believe that this sample of data is generalizable and the entire German start-up population. 
The mean is an indicator of a middle position that is reflected through all variables. As seen from the table, each variable has different mean thus inducing that each variable has a different intermediate point.

The standard deviation is used to evaluate the extent to which the data is spread from the mean. The higher the number of the standard deviation, the larger the sample of data will be spread from the mean point. We can take the first variable from table 2 which is "patents "we see that it has a mean of 0.06 and a standard deviation (SD) of 0.23 . this tells us that on average start-up have patents between -0.17 and 0.29 patents.

\section{Regression Output}

The full regression output is demonstrated through the analysis. There are two major variables that constantly resonate in the study, these are Innovation and Performance. Additionally, with the following results from the hypotheses, a test was carried out to determine whether the data collected will confirm or deny the theories provided from the conceptual model.

The t-test will be used to confirm if hypotheses can be accepted or rejected. This is a type of inferential statistic for linear regression, and used in statistics to determine if there is a significant difference between the means of two groups.

Consequently, the t-values ( $\mathrm{t}$ ) will be portrayed in the regression outputs, with its significant two-tail $\mathrm{p}$-value $(\mathrm{P}>\mathrm{t})$. This information will enable us to conduct the Null Hypothesis Significant Testing (NHST) at a significance (alpha- $\alpha$ ) level of 0.05 for all hypotheses. The confidence interval indicates the level of certainty that a certain range of values contains the true mean of the population. In our case we will be using the $95 \%$ confidence interval, equivalent to a level of significance of $\alpha=0.05$. This means that if any p-value is equal to $5 \%$ or smaller, we can consider the results to be statistically significant, thus allowing the rejection of the null Hypothesis $\left(H_{0}\right)$.

In conducting hypotheses testing, there is always a possibility of uncertainty in the results due to the fact that not all the data from all the start-ups from Germany is given, as the panel only provides the data for a big part of the population, thus having increasing the possibility of incorrect conclusions. This is why this paper believes that the study might arise Type I and Type II errors. As the risks of these type of errors are inversely related, both can be controlled using a specific level of significance set from the hypothesis testing. This would mean that if Type I error occurs in the study, it will reject the null hypothesis when it is actually true. For Type II error, it would mean that the failure to reject the null hypothesis when it would be false.

Based on the conceptual model and we were able to formulate the following Hypothesis: Hypothesis 1: the lower is the innovativeness of the startup, consequently, will have a negative correlation on start-up performance. 
To be able to compute the regression output of the variables the following formula was adopted:

$$
y i=\beta 0+\beta 1 x i+\epsilon i
$$

After computing the variables achieved in the resulting regression output table 5. We can interpret the following: if we look at the start-up population that have filed at least one patent between the years 2008-2016, we can say a start-up has one more patent in the sample period it would receive 149,605.1 euros per employee or more. Even if statistically a relevance is not found due to the low regression of 0.04 . There is an economical relevance to the results, since the mean for start-ups revenue per employee is of 342,935.5 euros. The study can deduce that having a patent has a positive influence in increase the revenue of a start-up. Furthermore, as "new product in the market" is used as the second variable as a representation of innovation we are faced with more result. The interpretation of these results states the following, if a start-up has 1 new product in the sample period, it will be able to receive 187,180 more euros per employee. In other words, both analyses clearly portray that having a new product or patent does give an advantage over competitors and will most likely will relate to positive monetary outcome.

Table 5: regression output of the studied variables

\begin{tabular}{|c|c|c|c|c|c|c|}
\hline $\begin{array}{c}\text { Performance } \\
\mathrm{y}\end{array}$ & Coef. & Std. err. & $\mathrm{t}$ & $\mathrm{P}>\mathrm{t}$ & $\begin{array}{c}{[95 \%} \\
\text { Conf. }\end{array}$ & Interval] \\
\hline Patents $\mathrm{x}$ & 149605.7 & 15825.42 & 9.45 & 0 & 118587.7 & 180623.6 \\
\hline
\end{tabular}

\begin{tabular}{|c|c|c|c|c|c|c|}
\hline Performance & Coef. & Std. err. & $\mathrm{t}$ & $\mathrm{P}>\mathrm{t}$ & $\begin{array}{c}{[95 \%} \\
\text { Conf. }\end{array}$ & Interval] \\
\hline $\begin{array}{c}\text { New } \\
\text { products }\end{array}$ & 187170 & 11988.19 & 15.61 & 0 & 163673 & 210666.9 \\
\hline
\end{tabular}

Now looking at the T-test for both regressions it can be said that: due to the fact that we have a value of 0 for both, we can reject the non-hypothesis in both cases. This mean that patents and new product have a significant effect on performance.

Hypothesis 2: investments have a direct positive influence on innovation, thus inducing a positive performance.

From the hypothesis results generated, we can analyze the following. Looking at the coefficient generated from the regression of the two variables of investment and patents table 5, if a start-up invests one more 1 euro as a result it will have 0.000000003 more patent than the general population in the sample period. Even if the result is not appealing, bear in mind that the number achieved will be for each euro invested into the company and looking at the mean that the start-ups invest each year it can be seen that it 38,756.08. Taking this number and multiplying it by the coefficient shows that it would result into 0.000116 . It must be taken into account that not all the investment of a business goes into creating new patents, so this could be the reason why such a small value was 
Table 5: regression output of the studied variables

\begin{tabular}{|c|c|c|c|c|c|c|}
\hline Patents & Coef. & Std. err. & $\mathrm{t}$ & $\mathrm{P}>\mathrm{t}$ & $\begin{array}{c}{[95 \%} \\
\text { Conf. }\end{array}$ & Interval] \\
\hline inv & $2.80 \mathrm{E}-08$ & $2.89 \mathrm{E}-09$ & 9.69 & 0 & $2.24 \mathrm{E}-08$ & $3.37 \mathrm{E}-08$ \\
\hline
\end{tabular}

\begin{tabular}{|c|c|c|c|c|c|c|}
\hline $\begin{array}{c}\text { New } \\
\text { products }\end{array}$ & Coef. & Std. err. & $\mathrm{t}$ & $\mathrm{P}>\mathrm{t}$ & $\begin{array}{c}{[95 \%} \\
\text { Conf. }\end{array}$ & Interval] \\
\hline inv & $1.67 \mathrm{E}-08$ & $3.84 \mathrm{E}-09$ & 4.36 & 0 & $9.20 \mathrm{E}-09$ & $2.42 \mathrm{E}-08$ \\
\hline
\end{tabular}

\begin{tabular}{|c|c|c|c|c|c|c|}
\hline Revenue & Coef. & Std. err. & $\mathrm{t}$ & $\mathrm{P}>\mathrm{t}$ & $\begin{array}{c}{[95 \%} \\
\text { Conf. }\end{array}$ & Interval] \\
\hline inv & $\begin{array}{c}0.418688 \\
7\end{array}$ & $\begin{array}{c}0.010701 \\
4\end{array}$ & 39.12 & 0 & $\begin{array}{c}0.397713 \\
9\end{array}$ & $\begin{array}{c}0.439663 \\
6\end{array}$ \\
\hline
\end{tabular}

achieved. However, we must take into consideration that each investment from start-ups is done for growth, to upgrade or develop further key components of the business to be able to have a competitive advantage.

Now looking at the hypothesis with the variable of new patents table 5 , this is the interpretation.

If a start-up invests 1 more euro in the business it will have 0.0000000016 more new product in the sample period. The same principle has to be applied here that we have to think that this number even if it's small it just for 1 euro invested.

In conclusion, looking at the regression between investment and revenue per employee, it can be said that for each euro invested, the start-up will receive 0.41 euros more, this proves that investing is a key factor for a business to grow and see positive monetary outcomes.

With the analysis of the T-test, it shows that: Between the variables of patents and innovation, the result of the $p$-value is 0.00 . This signifies that there is a significant effect from investments on patents, the same can be said with investment and new products as the p-value of 0.00 is seen. Knowing that the significant level is 0.05 , there is a significant effect between these two variables. Lastly, the last two variables have a p-value of 0.00 thus there is a significant effect between investment and revenue.

Given this information, it can be assumed that the p-value is lower than the significant level of 0.05 , consequently, rejecting the non-hypothesis.

To conclude, given the results of the data collected the theory stated by the hypothesis is confirmed, meaning that investments have a direct positive influence on innovation, also inducing a positive performance for the start-up. As Kerr \& Nanda (2015) have stated, 
investment impacts technological development, and its innovations by financing further promising ideas and thus shaping the nature of $R \& D$ that is undertaken.

This confirms the theory based on the data collected for the German start-up population.

Hypothesis 3: sector has a positive and a negative influence on innovation, depending on the sectors competitive environment, thus the relative innovativeness of a firm in the sector is a determinant of its performance.

This hypothesis will be analyzed in two different ways. Firstly, looking at the sector as an influencer on innovation, and secondly, looking at the sector as a determinate of performance throw innovation. Thus, firstly looking below at table 6

Table 6: Summary of the patents by sector $(*=$ both are part of the consumeroriented services)

Cutting-edge technology

\begin{tabular}{|c|c|c|}
\hline anzpat4 & freq. & percentage \\
\hline 0 & 3,951 & 85.15 \\
\hline 1 & 689 & 14.85 \\
\hline total & 4,640 & 100 \\
\hline
\end{tabular}

Technology-intensive services

\begin{tabular}{|c|c|c|}
\hline anzpat4 & freq. & percentage \\
\hline 0 & 12,002 & 94.02 \\
\hline 1 & 763 & 5.98 \\
\hline total & 12,765 & 100 \\
\hline
\end{tabular}

Other business-oriented services

\begin{tabular}{|c|c|c|}
\hline anzpat4 & freq. & percentage \\
\hline 0 & 3,778 & 97.62 \\
\hline 1 & 92 & 2.38 \\
\hline total & 3,870 & 100 \\
\hline
\end{tabular}

Construction

\begin{tabular}{|c|c|c|}
\hline anzpat4 & freq. & percentage \\
\hline 0 & 6,117 & 97 \\
\hline 1 & 189 & 3 \\
\hline total & 6,306 & 100 \\
\hline
\end{tabular}

Non-high-tech manufacturing

\begin{tabular}{|c|c|c|}
\hline anzpat4 & freq. & percentage \\
\hline 0 & 6,271 & 91.8 \\
\hline 1 & 560 & 8.2 \\
\hline total & 6,831 & 100 \\
\hline
\end{tabular}

High-tech manufacturing

\begin{tabular}{|c|c|c|}
\hline anzpat4 & freq. & percentage \\
\hline 0 & 3,103 & 80.2 \\
\hline 1 & 766 & 19.8 \\
\hline total & 3,869 & 100 \\
\hline
\end{tabular}

Software

\begin{tabular}{|c|c|c|}
\hline anzpat4 & freq. & percentage \\
\hline 0 & 4,971 & 95.39 \\
\hline 1 & 240 & 4.61 \\
\hline total & & \\
\hline
\end{tabular}

krea_KDL*

\begin{tabular}{|c|c|c|}
\hline anzpat4 & freq. & percentage \\
\hline 0 & 5,463 & 98.04 \\
\hline 1 & 109 & 1.96 \\
\hline total & 5,572 & 100 \\
\hline
\end{tabular}

Wholesale and retail market

\begin{tabular}{|c|c|c|}
\hline anzpat4 & freq. & percentage \\
\hline 0 & 1,017 & 96.86 \\
\hline 1 & 33 & 3.14 \\
\hline total & 1,050 & 100 \\
\hline
\end{tabular}

Skill-intensive services

\begin{tabular}{|c|c|c|}
\hline anzpat4 & freq. & percentage \\
\hline 0 & 4,512 & 96.02 \\
\hline 1 & 187 & 3.98 \\
\hline total & 4,699 & 100 \\
\hline
\end{tabular}


sonst_KDL*

\begin{tabular}{|c|c|c|}
\hline anzpat4 & freq. & percentage \\
\hline 0 & 6,128 & 99.01 \\
\hline 1 & 61 & 0.99 \\
\hline total & 6,189 & 100 \\
\hline
\end{tabular}

The sector that register most of the patents and has the highest percentage of cutting-edge technology manufacturing with $14 \%$ and High-technology manufacturing with $19 \%$ respectively. This tells us that the more technology-based sectors have more innovative environment thus further subjected to common innovativeness. On the other end of the spectrum, the consumer-oriented services (sonst_KDL) has the least with 16 patents registered which is $0.99 \%$ of the sector sample population. This leads to the belief that environments involved with technology, where there is a continuous research for new product and invention enabling better service or product to increase the company competition advantage, will definitely be more involved with innovation.

Now, looking at new product in the market (Table 7), a similar phenomenon has occurred. The sectors that have the highest percentages of new products are again cutting-edge technology manufacturing with $776=16 \%$ and High technology manufacturing with 837 $=21 \%$ but there is also the software sector with $920=17 \%$. Looking at the other side of the spectrum, with the smallest percentage we have (sost_KDL) consumer-oriented services with $216=3.5 \%$. Consequently, it can be stated that new product sectors are dependent on their environmental innovativeness.

Table 7: Summary of the patents by sector (*both are part of the consumer-oriented services)

Cutting-edge technology manufacturing

\begin{tabular}{|c|c|c|}
\hline mneu2 & freq. & percentage \\
\hline 0 & 3,864 & 83.28 \\
\hline 1 & 776 & 16.72 \\
\hline total & 4,640 & 100 \\
\hline
\end{tabular}

Technology-intensive manufacturing

\begin{tabular}{|c|c|c|}
\hline mneu2 & freq. & percentage \\
\hline 0 & 11,388 & 89.21 \\
\hline 1 & 1,377 & 10.79 \\
\hline total & 12,765 & 100 \\
\hline
\end{tabular}

Other business-oriented services

\begin{tabular}{|c|c|c|}
\hline mneu2 & freq. & percentage \\
\hline 0 & 3,581 & 92.53 \\
\hline 1 & 289 & 7.47 \\
\hline total & 3,870 & 100 \\
\hline
\end{tabular}

High-technology manufacturing

\begin{tabular}{|c|c|c|}
\hline mneu2 & freq. & percentage \\
\hline 0 & 3,032 & 78.37 \\
\hline 1 & 837 & 21.63 \\
\hline total & 3,869 & 100 \\
\hline
\end{tabular}

\begin{tabular}{|c|c|c|}
\multicolumn{3}{|c}{ Software } \\
\hline mneu2 & freq. & percentage \\
\hline 0 & 4,291 & 82.35 \\
\hline 1 & 920 & 17.65 \\
\hline total & 5,211 & 100 \\
\hline
\end{tabular}

krea_KDL*

\begin{tabular}{|c|c|c|}
\hline mneu2 & freq. & percentage \\
\hline 0 & 5,073 & 91.04 \\
\hline 1 & 499 & 8.96 \\
\hline total & 5,572 & 100 \\
\hline
\end{tabular}

Wholesale and retail market 
Construction

\begin{tabular}{|c|c|c|}
\hline mneu2 & freq. & percentage \\
\hline 0 & 5,821 & 92.31 \\
\hline 1 & 485 & 7.69 \\
\hline total & 6,306 & 100 \\
\hline
\end{tabular}

Non-high-tech industries

\begin{tabular}{|c|c|c|}
\hline mneu2 & freq. & percentage \\
\hline 0 & 6,066 & 88.8 \\
\hline 1 & 765 & 11.2 \\
\hline total & 6,831 & 100 \\
\hline
\end{tabular}

Skill-intensive services

\begin{tabular}{|c|c|c|}
\hline mneu2 & freq. & percentage \\
\hline 0 & 4,219 & 89.79 \\
\hline 1 & 480 & 10.21 \\
\hline total & & 100 \\
\hline
\end{tabular}

\begin{tabular}{|c|c|c|}
\hline mneu2 & freq. & percentage \\
\hline 0 & 961 & 91.52 \\
\hline 1 & 89 & 8.84 \\
\hline total & 1,050 & 100 \\
\hline
\end{tabular}

sonst_KDL*
\begin{tabular}{|c|c|c|}
\hline mneu2 & freq. & percentage \\
\hline 0 & 5,973 & 96.51 \\
\hline 1 & 216 & 3.49 \\
\hline total & 6,189 & 100 \\
\hline
\end{tabular}

In the analysis of each sectors' behavior between their relative innovation towards the performance the following can be discussed:

Looking at the most innovation intensive sector which is cutting-edge technology manufacturing,

$>$ branche $=$ Cutting-edge technology manufacturing

\begin{tabular}{|c|c|c|c|c|c|c|}
\hline ums & Coef. & Std. Err. & $\mathrm{t}$ & $\mathrm{P}>\mathrm{t}$ & {$[95 \%$ Conf. } & Interval] \\
\hline anzpat4 & 66443.57 & 32156.79 & 2.07 & 0.039 & 3397.752 & 129489.4 \\
\hline
\end{tabular}

it can be said that with one more patent in the sample period a start-up will raise $66,443.57$ euros per employee or more. This shows that in that sector having a patent does have an effect on performance as it can bring greater revenues to a start-up.

$->$ branche $=$ (sonst_KDL) consumer- oriented services

\begin{tabular}{|c|c|c|c|c|c|c|}
\hline ums & Coef. & Std. Err. & $\mathrm{t}$ & $\mathrm{P}>\mathrm{t}$ & [95\% Conf. & Interval] \\
\hline anzpat4 & 430152.1 & 124917.2 & 3.44 & 0.001 & 185261.5 & 675042.8 \\
\hline
\end{tabular}

For the less innovative, 1 more patent in the sample period the start-up will receive 430,152.1 euros per employees or more. Knowing that the mean for this sector is $354,795.6$ revenues per employee, means that in this sector being able to produce a patent will have a greater effect than if you produce a patent in the cutting-edge technology manufacturing sector.

Interestingly from this result we can further perceive that two sectors, Software, and Wholesale and retail market, have a negative outcome for performance. The software 
sector which has $4 \%$ of the population having patents, has been found to have one more patent in the sample period resulting in $-19,151.86$ euros per employee, and the mean is of 22,966.1 euros per employee. This determines that having a patent is not good approach economically for a start-up to pursue, as patents are not valuable enough to pursue. The liability of this result lays also on the way that patents provide a valuable protection system for that new software. As in general when patent a software, the software is not, in itself a patent, but the method or algorithm that accomplished the end result. Thus, this can be a major reason for the negative result as companies can easily bypass the protection by creating new codes and algorithms and end up with the same result.

The other sector is the Wholesale and retail market which concluded that having one more patent in the sample period will result in $-176,673.4$ euros per employee. This is due to the fact that in this sector is defined as the distribution arrangement that constitutes a major part of the supply chain. Thus, they do not produce or make service or product, but are the distribution channel for those. This means that trying to create patents and new product in this sector are manly to increase efficiency of the supply chain.

Examining the new product performance, it can be said that for Cutting-edge technology manufacturing,

branche $=$ Cutting-edge technology manufacturing

\begin{tabular}{|c|c|c|c|c|c|c|}
\hline ums & Coef. & Std. Err. & $\mathrm{t}$ & $\mathrm{P}>|\mathrm{t}|$ & [95\% Conf. & Interval] \\
\hline mneu2 & 226042.6 & 30602.14 & 7.39 & 0 & 166044.7 & 286040.4 \\
\hline
\end{tabular}

having one newer product in the sample period will have 226,042.6 euros more per employee. Knowing that the average is 330,006.2 euros per employee, shows that this has a significant effect in this sector to have a new product as it would bring massive amount of revenues.

Looking at the one with the highest percentage which is high-technology manufacturing, We can say that 1 newer product in the sample period will bring 119,077.1 euros of revenue per employee more to the start-up.

branche $=$ High technology manufacturing

\begin{tabular}{|c|c|c|c|c|c|c|}
\hline ums & Coef. & Std. Err. & $\mathrm{t}$ & $\mathrm{P}>|\mathrm{t}|$ & {$[95 \%$ Conf. } & Interval] \\
\hline mneu2 & 119077.1 & 45417.88 & 2.62 & 0.009 & 30027.09 & 208127.1 \\
\hline
\end{tabular}

Furthermore, in this case software will not have a negative result but a very impressive result as 1 newer product in the sample period will generate 202,003.2 euros more revenue per employee. Thus, also confirming the theory that patents can be easily buy past in this sector.

\begin{tabular}{|c|c|c|c|c|c|c|}
\hline ums & Coef. & Std. Err. & $\mathrm{t}$ & $\mathrm{P}>|\mathrm{t}|$ & {$[95 \%$ Conf. } & Interval $]$ \\
\hline mneu2 & 202003.2 & 18183.03 & 11.11 & 0 & 166355.5 & 237650.9 \\
\hline
\end{tabular}


Now looking at the least innovative sector which is (sost_KDL) consumer-oriented services, there still is a positive outcome with a coefficient of 237,297.7. Knowing the mean which is of 354,795.6 we can say that economically speaking even if this sector is not really innovative having new products does help improve the performance.

branche $=$ consumer-oriented services

\begin{tabular}{|c|c|c|c|c|c|c|}
\hline ums & Coef. & Std. Err. & $\mathrm{t}$ & $\mathrm{P}>|\mathrm{t}|$ & {$[95 \%$ Conf. } & Interval] \\
\hline mneu2 & 237297.7 & 65746.25 & 3.61 & 0 & 108407.2 & 366188.2 \\
\hline
\end{tabular}

In the analysis of the p-values, all the results are lower than the significant level of 0.05 , leading to the rejection of the null hypothesis, and accepting the theory stated from the hypothesis.

Given the information above, it can be said that this sector has a positive and a negative influence on innovation as seen from the different outcomes shown in table 6 and 7 . Remarkably, this difference in innovation intensity can affect the performance of the startup in different degrees, as shown in the case of cutting edge technology sector and the consumer-oriented services, where the difference in revenue per employee from one more patent, see the less innovative sector with a much higher return of 430,152.1 in contrast of to the most innovative with $66,443.57$.

Therefore, in more innovative sectors, innovation is necessary to survive the competitive environment and subsequently boost the performance of the business, but less innovative intensive sectors, innovation can really make the difference between dominating the market or being a substandard business.

Hypothesis 4: Start-up size has a positive influence on the start-up innovativeness.

From the data collection the subsequent results were found as portrayed on the table below.

Having one more worker will result in having 0.00177 more patent in the sample period, it must be noted that this is the result of only one worker.

\begin{tabular}{|c|c|c|c|c|c|c|}
\hline patent & Coef. & Std. Err. & $\mathrm{t}$ & $\mathrm{P}>|\mathrm{t}|$ & [95\%Conf. & Interval] \\
\hline size & 0.0017736 & 0.0001659 & 10.69 & 0 & 0.0014485 & 0.0020988 \\
\hline
\end{tabular}

\begin{tabular}{|c|c|c|c|c|c|c|}
\hline N. product & Coef. & Std. Err. & $\mathrm{t}$ & $\mathrm{P}>|\mathrm{t}|$ & [95\% Conf. & Interval] \\
\hline Size & 0.0031082 & 0.0002247 & 13.83 & 0 & 0.0026677 & 0.0035487 \\
\hline
\end{tabular}

Looking at new product, the research has found that having 1 more worker will give the possibility to have 0.003 more new product. Knowing that the mean for new product is 0.11 shows that increasing the number of employees will help a start-up with constructing 
new ideas for new products, ultimately resulting in the possibility of developing that unforeseen innovations.

Looking at the p-value of these regressions, both of the regressions are lower than the significant level of 0.05 , indicating the rejection of the null hypothesis.

To conclude, as the null hypothesis was rejected, the theory of the hypothesis is accepted. This implies that start-ups with the ability to expand their workforce size should do so, as it can increase the possibility of generating knowledge, reducing research time, and increasing the growth that the start-up is seeking.

Hypothesis 5: the start-up that 1) have the founders with academic qualification and 2) have a high percentage of graduated employees are more likely than other start-ups to 1) innovate and 2) perform better.

From Table 8 it can be determined that the subsequent result from two very important variables share very similar principals which is knowledge. We will discuss the knowledge that a founder can bring into the business and also the knowledge that the start-up can acquire.

Table 8: Regression outputs of the variables

\begin{tabular}{|c|c|c|c|c|c|c|}
\hline Patents & Coef. & Std. Err. & $\mathrm{t}$ & $\mathrm{P}>|\mathrm{t}|$ & {$[95 \%$ Conf. } & Interval] \\
\hline $\begin{array}{c}\text { Founder } \\
\text { H.Q. }\end{array}$ & 0.03136 & 0.0010284 & 30.49 & 0 & 0.0293442 & 0.0333757 \\
\hline
\end{tabular}

\begin{tabular}{|c|c|c|c|c|c|c|}
\hline N. Products & Coef. & Std. Err. & $\mathrm{t}$ & $\mathrm{P}>|\mathrm{t}|$ & {$[95 \%$ Conf. } & Interval] \\
\hline $\begin{array}{c}\text { Founder } \\
\text { H.Q. }\end{array}$ & 0.0380047 & 0.0013557 & 28.03 & 0 & 0.0353475 & 0.0406618 \\
\hline
\end{tabular}

\begin{tabular}{|c|c|c|c|c|c|c|}
\hline Revenue & Coef. & Std. Err. & $\mathrm{t}$ & $\mathrm{P}>|\mathrm{t}|$ & {$[95 \%$ Conf. } & Interval] \\
\hline $\begin{array}{c}\text { Fonder } \\
\text { H.Q. }\end{array}$ & 69904.36 & 4205.439 & 16.62 & 0 & 61661.66 & 78147.06 \\
\hline
\end{tabular}

\begin{tabular}{|c|c|c|c|c|c|c|}
\hline Patents & Coef. & Std. Err. & $\mathrm{t}$ & $\mathrm{P}>|\mathrm{t}|$ & {$[95 \%$ Conf. } & Interval] \\
\hline Graduates & 0.0078333 & 0.0004127 & 18.98 & 0 & 0.0070243 & 0.0086422 \\
\hline
\end{tabular}

\begin{tabular}{|c|c|c|c|c|c|c|}
\hline N. products & Coef. & Std. Err. & $\mathrm{t}$ & $\mathrm{P}>|\mathrm{t}|$ & [95\% Conf. & Interval] \\
\hline Graduates & 0.0197516 & 0.0005653 & 34.94 & 0 & 0.0186437 & 0.0208596 \\
\hline
\end{tabular}

We will firstly examine the result for the founder's academic qualification and patents. As seen from the regression it can be interpreted as: if one start-up has one more founder with a higher qualification, it will result in the start-up having 0.03 more patent in the sample period. Even if is not massive it still a good result as it means that the founder can have a big impact on the generating ideas. 
Now looking into new product, the result portrays that if the start-up has one more founder with higher qualification it will result in having 0.038 more new products.

In terms of performance, for a start-up to have one more founder with higher qualification will result in having 69,904.36 euros more of revenue per employee. Good decision making and knowledge of the market that could ensue in this increase in revenue.

Looking at the variable of employees with degrees, the following results have been discovered: if a company hires one more employee with a degree it will have 0.0078 more patent in the sample period. The data for new product results that that having one more employee with a degree will lead to 0.019 more new products. These results are encouraging for start-up as it can help them to further increase their innovativeness by increasing their number of graduated workers, which is a key for a business to have an innovative workforce.

In order to confirm this hypothesis, an analysis of the p-values must be done testing if the theory is right or not. Given at all the p-values retrieved from the data collected, it can be said that they are all lower than the statistically significant value of 0.05 , therefore rejecting the null hypothesis $\left(H_{0}\right)$.

After the hypothesis testing, hypothesis 5 can be accepted. Hence we observe that the start-ups that have one or more founders with academic qualification and a high percentage of graduate workers are more likely to innovate and perform than other startups. The combination of the founder knowledge and the workforce academic experience can lead to a greater gathering and recognition of new and undiscovered opportunities, that could in fact change the market competitive environment, consequently increasing the performance of the start-up that could exploit this opportunity.

Hypothesis 6: founders' highest qualification that correspond the sector/industry of his/her business has a positive correlation to innovativeness of the startup.

Looking at literature about the founder's qualification, it is seen that if a founder has a degree or qualification that resonates the most to the sector it will have higher change to develop a patent than the rest of the sector start-ups.

Having a University degree in economics/ business science will result that in sector this degree has the most impact on the sectors of technology-intensive services. This shows that having at least one founder with a degree in economics/ business science will receive 0.033 patents in the technology-intensive services sector.

branche $=$ technology-intensive services

\begin{tabular}{|l|c|c|c|c|c|c|}
\hline \multicolumn{1}{|c|}{ Patents } & Coef. & Std. Err. & $\mathrm{t}$ & $\mathrm{P}>|\mathrm{t}|$ & {$[95 \%$ Conf. } & Interval] \\
\hline bwl & .0337532 & 0.0077695 & 4.34 & 0 & 0.0185229 & 0.0489835 \\
\hline
\end{tabular}


A degree in natural science has the most impact in the sectors of non-high-tech manufacturing with the respective coefficient of 0.144 . This signifies that having a founder with this degree will offer 0.144 more patents in the sector of non-high-tech.

$->$

branche $=$ non-high-tech manufacturing

\begin{tabular}{|c|c|c|c|c|c|c|}
\hline Patents & Coef. & Std. Err. & $\mathrm{t}$ & $\mathrm{P}>|\mathrm{t}|$ & [95\% Conf. & Interval] \\
\hline natur & .1447524 & 0.0274639 & 5.27 & 0 & 0.0908915 & 0.1986134 \\
\hline
\end{tabular}

With a math/ computer science degree in the sector of non-high-tech manufacturing means that having one founder with math/computer science degree will result in having 0.055 more patent.

non-high-tech manufacturing

\begin{tabular}{|c|c|c|c|c|c|l|}
\hline Patent & Coef. & Std. Err. & $\mathrm{t}$ & $\mathrm{P}>|\mathrm{t}|$ & {$[95 \%$ Conf. } & Interval] \\
\hline mathinf & .0556854 & 0.0434051 & 1.28 & 0.2 & -0.0294386 & 0.1408093 \\
\hline
\end{tabular}

For a degree in Engineering Science, we have the sectors of wholesale and retail market with the respective coefficient of 0.07 . thus, showing that having one founder with a degree in Engineering Science it will obtain 0.07 more patent in the whole and retail market sector.

->

branche $=$ wholesale and retail market

\begin{tabular}{|l|c|c|c|c|c|c|}
\hline \multicolumn{1}{|c|}{ Patent } & Coef. & Std. Err. & $\mathrm{t}$ & $\mathrm{P}>|\mathrm{t}|$ & $\begin{array}{c}{[95 \%} \\
\text { Conf. }\end{array}$ & Interval] \\
\hline ingwiss & .074722 & 0.0221217 & 3.38 & 0.001 & 0.0311819 & 0.118262 \\
\hline
\end{tabular}

Another field of study which has a major effect has been seen on the sector of Cuttingedge technology manufacturing with a coefficient of 0.11 .

\begin{tabular}{|c|c|c|c|c|c|c|}
\hline Patent & Coef. & Std. Err. & $\mathrm{t}$ & $\mathrm{P}>|\mathrm{t}|$ & {$[95 \%$ Conf. } & Interval] \\
\hline fach_sonst & .113157 & 0.0367408 & 3.08 & 0.002 & 0.0411033 & 0.1852107 \\
\hline
\end{tabular}

Subsequently, each of the qualification has one sector in which they are most effective when producing an innovation and for each of those we be displayed here below:

Mercantile professions

->branche $=$ Cutting-edge technology manufacturing

\begin{tabular}{|c|c|c|c|c|c|c|}
\hline Patent & Coef. & Std. Err. & $\mathrm{t}$ & $\mathrm{P}>|\mathrm{t}|$ & {$[95 \%$ Conf. } & Interval] \\
\hline kaufmann & .2324434 & 0.0155241 & 14.97 & 0 & 0.2020035 & 0.2628833 \\
\hline
\end{tabular}

Technical professions

$>\quad$ branche $=$ Cutting-edge technology manufacturing

\begin{tabular}{|c|c|c|c|c|c|c|}
\hline Patent & Coef. & Std. Err. & $\mathrm{t}$ & $\mathrm{P}>|\mathrm{t}|$ & {$[95 \%$ Conf. } & Interval] \\
\hline techniker & .0625895 & 0.0112206 & 5.58 & 0 & 0.0405879 & 0.084591 \\
\hline
\end{tabular}




\section{Social professions}

$\rightarrow$

branche $=$ Technology-intensive services

\begin{tabular}{|c|c|c|c|c|c|l|}
\hline Patent & Coef. & Std. Err. & $\mathrm{t}$ & $\mathrm{P}>|\mathrm{t}|$ & [95\% Conf. & Interval] \\
\hline sozial & .0676182 & 0.0164577 & 4.11 & 0 & 0.035354 & 0.0998823 \\
\hline
\end{tabular}

Hotel and restaurant industry

->

branche $=$ Software

\begin{tabular}{|c|c|c|c|c|c|l|}
\hline Patent & Coef. & Std. Err. & $\mathrm{t}$ & $\mathrm{P}>|\mathrm{t}|$ & [95\% Conf. & Interval] \\
\hline sonst_DL & .1891189 & 0.024798 & 7.63 & 0 & 0.140482 & 0.2377559 \\
\hline
\end{tabular}

Other professions

$>$ branche $=$ Cutting-edge technology manufacturing

\begin{tabular}{|c|c|c|c|c|c|c|}
\hline Patent & Coef. & Std. Err. & $\mathrm{t}$ & $\mathrm{P}>|\mathrm{t}|$ & [95\% Conf. & Interval] \\
\hline sonst_beruf & .3870067 & 0.0357493 & 10.83 & 0 & 0.3169088 & 0.4571047 \\
\hline
\end{tabular}

Looking at the new patents, we will see the following tables below to be the most effective highest qualification to produce a new product in each sector:

\section{Economic/Business Studies}

$->$

branche $=$ Technology-intensive services

\begin{tabular}{|c|c|c|c|c|c|c|}
\hline N. Product & Coef. & Std. Err. & $\mathrm{t}$ & $\mathrm{P}>|\mathrm{t}|$ & {$[95 \%$ Conf. } & Interval] \\
\hline bwl & .0674339 & 0.0095085 & 7.09 & 0 & 0.0487947 & 0.0860731 \\
\hline
\end{tabular}

\section{Natural Science Studies}

$\rightarrow$

branche $=$ non-high-tech manufacturing

\begin{tabular}{|c|c|c|c|c|c|c|}
\hline N. Product & Coef. & Std. Err. & $\mathrm{t}$ & $\mathrm{P}>|\mathrm{t}|$ & {$[95 \%$ Conf. } & Interval] \\
\hline natur & .1316434 & 0.029718 & 4.43 & 0 & 0.0733618 & 0.189925 \\
\hline
\end{tabular}

\section{Math/Computer science}

$->$

branche $=$ Cutting-edge technology manufacturing

\begin{tabular}{|c|c|c|c|c|c|c|}
\hline N. Product & Coef. & Std. Err. & $\mathrm{t}$ & $\mathrm{P}>|\mathrm{t}|$ & {$[95 \%$ Conf. } & Interval] \\
\hline mathinf & .0772918 & 0.0389698 & 1.98 & 0.047 & 0.0008667 & 0.153717 \\
\hline
\end{tabular}

\section{Engineering Studies}

->

branche $=$ wholesale and retail market

\begin{tabular}{|l|c|l|c|c|c|l|}
\hline N. Product & Coef. & Std. Err. & $\mathrm{t}$ & $\mathrm{P}>|\mathrm{t}|$ & [95\% Conf. & Interval] \\
\hline ingwiss & .0460496 & 0.0428089 & 1.08 & 0.283 & -0.0382072 & 0.1303063 \\
\hline
\end{tabular}




\section{Other Studies}

-> branche $=$ technology-intensive services

\begin{tabular}{|c|c|c|c|c|c|c|}
\hline N. Product & Coef. & Std. Err. & $\mathrm{t}$ & $\mathrm{P}>|\mathrm{t}|$ & {$[95 \%$ Conf. } & Interval] \\
\hline fach_sonst & .0550192 & 0.0145945 & 3.77 & 0 & 0.0264103 & 0.0836282 \\
\hline
\end{tabular}

\section{Mercantile profession}

branche $=$ Cutting-edge technology manufacturing

\begin{tabular}{|c|c|c|c|c|c|c|}
\hline N. Product & Coef. & Std. Err. & $\mathrm{t}$ & $\mathrm{P}>|\mathrm{t}|$ & {$[95 \%$ Conf. } & Interval] \\
\hline kaufmann & .098986 & 0.0191399 & 5.17 & 0 & 0.0614561 & 0.1365159 \\
\hline
\end{tabular}

Technical profession

$\rightarrow$

branche $=$ Cutting-edge technology manufacturing

\begin{tabular}{|l|l|l|l|c|c|c|}
\hline N. Product & Coef. & Std. Err. & $\mathrm{t}$ & $\mathrm{P}>|\mathrm{t}|$ & {$[95 \%$ Conf. } & Interval] \\
\hline techniker & .0736494 & 0.0133727 & 5.51 & 0 & 0.0474281 & 0.0998708 \\
\hline
\end{tabular}

Social Professions

->

branche $=$ non-high-tech manufacturing

\begin{tabular}{|l|c|c|c|c|c|c|}
\hline N. Product & Coef. & Std. Err. & $\mathrm{t}$ & $\mathrm{P}>|\mathrm{t}|$ & {$[95 \%$ Conf. } & Interval] \\
\hline sozial & .1061526 & 0.0261511 & 4.06 & 0 & 0.0548849 & 0.1574202 \\
\hline
\end{tabular}

Hotel and Restaurant Industry

branche $=($ sonst_KDL $)$ Consumer oriented services

\begin{tabular}{|c|c|c|c|c|c|c|}
\hline N. Product & Coef. & Std. Err. & $\mathrm{t}$ & $\mathrm{P}>|\mathrm{t}|$ & [95\% Conf. & Interval] \\
\hline sonst_DL & .0643353 & 0.0134234 & 4.79 & 0 & 0.0380196 & 0.0906509 \\
\hline
\end{tabular}

Other professions

$->$ branche $=$ Cutting-edge technology manufacturing

\begin{tabular}{|r|r|r|r|r|r|r|}
\hline N. Product & Coef. & Std. Err. & $\mathrm{t}$ & $\mathrm{P}>|\mathrm{t}|$ & [95\% Conf. & Interval] \\
\hline sonst_beruf & .1254799 & 0.0434252 & 2.89 & 0.004 & 0.0403309 & 0.2106289 \\
\hline
\end{tabular}

In conclusion, in analyzing the p-values to confirm or reject the hypothesis we would not be able to find an answer, but can only confirm by looking at the qualification and the sector. Nevertheless, as the qualification and the sector do not have a direct link between each other it is very difficult to establish a table that can do so. Consequently, this hypothesis cannot be tested, however the finding is still very interesting to demonstrate in the research. It can give a very interesting view for future entrepreneurs on how their qualification may perform in each sector, and more interestingly in which sector would they perform the best, when trying to innovate the business. 
Hypothesis 7: start-up that used support services of startup centers have a higher innovativeness and performance than other startups

The analysis of these variables will determine if start-ups are better off starting their early years with the support of start-up center/incubator or without any support. The result exhibits that having support from an incubator will result in 0.12 more patents in the sample period and in the case of new product the start-up will have an increase of 0.08 new product (table 9). This result shows that having an incubator and the access to scientific, technical, and professional experts supports entrepreneurs in generating new intellectual property.

Looking at the performance side from a start-up which had support from a start-up, the result is not appealing as it results that $-128,188.9$ euros per employee will be received. Thus incubators are given many tools to progress in the construction of the business but when these start-ups leave that safe zone, they would be not well prepared in their respective market leading to the negative performance of the business.

\begin{tabular}{|c|c|c|c|c|c|c|}
\hline Patent & Coef. & Std. Err. & $\mathrm{t}$ & $\mathrm{P}>|\mathrm{t}|$ & $\begin{array}{c}{[95 \%} \\
\text { Conf. }\end{array}$ & Interval] \\
\hline Start-up center & 0.1215844 & 0.0204852 & 5.94 & 0 & 0.0814131 & 0.1617558 \\
\hline
\end{tabular}

\begin{tabular}{|c|c|c|c|c|c|c|}
\hline N. Product & Coef. & Std. Err. & $\mathrm{t}$ & $\mathrm{P}>|\mathrm{t}|$ & $\begin{array}{c}{[95 \%} \\
\text { Conf. }\end{array}$ & Interval] \\
\hline Strat-up center & 0.0819153 & 0.0279159 & 2.93 & 0.003 & 0.0271723 & 0.1366583 \\
\hline
\end{tabular}

\begin{tabular}{|c|c|c|c|c|c|c|}
\hline Performance & Coef. & Std. Err. & $\mathrm{t}$ & $\mathrm{P}>|\mathrm{t}|$ & $\begin{array}{c}{[95 \%} \\
\text { Conf. }\end{array}$ & Interval $]$ \\
\hline Start-up center & -128188.9 & 73069.72 & -1.75 & 0.08 & -271485.5 & 15107.78 \\
\hline
\end{tabular}

Table 9: Regression outputs of the variables

Observing the result of the p-values of the regression will determine whether the hypothesis can be accepted or denied; accordingly, in examining the p-values it can be seen that, for the regressions of start-up centers and innovation, both values are lower than the significant level of 0.05 there more meaning that a start-up center does have an effect in supporting start-up in innovating. An interesting result has been discovered for the pvalue between the start-up centers and revenue, since the p-value is higher than the significant level of 0.05 thus accepting the null hypothesis.

Given the information, the hypothesis that start-ups that used support services of start-up centers can affect positively their innovativeness, is partially rejected. It is accepted that a start-up center does have an effect in patents and new products leading to the belief that they support and offer more innovativeness. It is rejected that start-up center services later on create any positive performance for those start-ups as we can see from the negative coefficient of-128,188.9, Thus, it might not be very tempting for entrepreneurs to look 
into this option when starting in a new business, even though there are very good constructive innovative results.

\section{Discussion}

The dataset does not explicitly mention any of its limitations, however, some limitations were spotted when conducting this study. Future research can address these limitations. Firstly, even though the database offered a big dataset with many variables, the sample did not offer a clear and rich measure of innovation; the variables proposed are crude. Secondly, there is the lack of information of the start-ups, as start-ups had the right decide to not answer questions consequently affecting the data. In the research it was noticed that this pattern was more frequent for sensitive information such as patents, new product and so forth. This limited the research as the data set by constructing codes to tackle the issues had to be altered, resulting in a less accurate but more effective results.

Thirdly, due to the data set having highly sensitive information, the start-up data panel has decided to 'truncation'. As explained in appendix 1, this means that the results were limited to a certain extent to ensure anonymity, which has affected the research as it modified the data thus it cannot be ensured that the result are $100 \%$ correct for the entire population. Nevertheless, as mentioned, the sample is representative of the population, due to the sample size being so large. It has been found that there are significant relationships between the data and all the variables studied, which was ensured to be very precise with the results. Lastly, there is no direct connection between qualification \& sector limiting our research, as it would have been of great use to be able to conduct the null hypothesis testing for hypothesis 6 .

To conclude, future studies could address some of the issues mentioned. Furthermore, it would be advised to refine the research, for example by studying the variation within firms that have followed the specific pattern of innovation. A more extended start-up data set panel could observe various start-ups in different international markets and study if the phenomena can be comparable through different international market. With this insight it would not just help entrepreneurs in Germany but also entrepreneurs around the world.

Lastly, future research could include more variables that can measure innovation. More variables could be included that might increase the changes of innovating, to have a greater insight on this topic, and create knowledge that can be very helpful to any future entrepreneur that wants to start a business.

\section{Conclusion}

This research paper examined whether innovation affects a start-up's performance to prevent its failure. The study investigated the relationships between the main variables of start-ups that impact innovation such as: (investments, industry, size, graduated employees, support of incubators and founder highest qualification), innovations and performance. The study followed a quantitative data analysis to obtain the results. A 
thorough literature review was done to come up with the variables. The statistical significance of the hypotheses was tested to complete the null hypothesis significance testing. Furthermore, an analysis of the regression output, originating from the primary source of the start-up data panel, was conducted. In the hypothesis testing, the $95 \%$ confidante interval was considered, giving a significance level of 0.05 . Given the agreeing p-values, the null hypothesis $H_{0}$ for hypothesis 1-5 were rejected, confirming the conceptual findings. Then, the null hypothesis $H_{0}$ of the seventh hypothesis was partially rejected. This shows that services of start-up centers create higher innovativeness in startups, as a significant effect on innovation. However, it does not provide a significant effect that start-up centers support does not impact positively the performance of the start-up that used the service. Moreover, hypothesis 6 could not be tested, but nevertheless it provided some insights on each sector and the most efficient qualification, with even some cases that we would have not expected.

Thus, after conducting the research we express the following statistically significant findings of the research:

1. Patents and new product have a significant impact on performance, thus leading to the belief that the lower the innovativeness the smaller the performance.

2. Investments have a direct positive influence on innovation, thus inducing a positive performance. This means that start-ups should aim to invest as much as possible in the early stages to have an innovative advantage in the market in the future.

3. Industry has a positive and a negative influence on innovation. The relative innovativeness of a firm in the industry is a determinant of its performance is dependent on the industry's competitive environment.

4. Start-up size has a positive influence on the start-up innovativeness.

5. A start-up with founders with academic qualification and high percentage of graduate workers are more likely to innovate and perform better.

Interestingly for some of the hypotheses, the data panel failed or was not able to confirm the research framework model of the study. Additionally, based on rational thinking, when looking at the result of hypothesis 6 , the research expects that founders that have a high qualification in a field would be more effective in creating opportunities for innovation in a sector that would be considered similar to its qualification. The founders have better knowledge on the market thus are able to effectively identify environmental business changes which can induct into market exploitation opportunities.

For hypothesis 7, we would think that start-ups that that used services such as incubators or start-up center would be more successful, as they are helped by professionals, most of the tools needed are given to run the business, they have the facilities, and most importantly they are set in an entrepreneurs environment. However, it appears that these tools help the start-up being more innovative, but in fact still produce a start-up that performs very poorly. 
To answer the research question, it is concluded that innovation does affect the start-up performance in many ways. Firstly, the investment variable, a fundamental factor in a start-up path for growth, the more investment a start-up can raise the more it will have to spend on developing its facilities, invest in research, more skilled employees and so on. Thus, ultimately having more possibilities enabling the development of new products and pattens that can make the difference as competitive advantage. Secondly, we have the industry which plays a very important role. Depending on the industry that the start-up is operating in, the standard innovativeness can change. Nevertheless, this does not mean that if a sector is more innovative, that the innovation in that sector will be more effective consequently producing a high revenue, on the contrary the less innovative the sector the higher the effectiveness of the innovation.

Thirdly, we have the size of a start-up. The more employees the start-up has, the greater the effect that delimits the innovativeness. Additionally, size can tell a lot about a start-up, as a bigger the size means that the company is doing well financially as it has more tools to hire more employees, therefore inducing in a greater gathering of more vital information which can turn out to be unforeseen innovations by the part of the company.

Fourthly, founders with an academic qualification and graduate employees are very important, as they are the most direct variable that go hand in hand with innovation. Founders with a degree qualification and up to date knowledge can help in creating innovation and steering the company to success. Additionally, graduate workers are a driver for the company as they are the workforce that implement and generates the ideas to enable the best possible outputs to produce the 'best products.

Finally, we have start-up centers, these types of services can be fundamental for an entrepreneur. Mostly, for very young and inexperienced ones, as these centers give the tools for the entrepreneur and the startup to vision their ideas, furthermore they supply constant knowledge and employees that can help in creating the new products that the industry has still yet to see.

In conclusion, we believe that this research has given a valuable contribution on existing academic literature. It gives thought-provoking and relevant insight in the mechanism of the start-up. Most importantly, on what entrepreneurs should do to limit it failure, an area where there is no clear literature.

\section{References:}

Acs, Z. J., \& Audretsch, D. B. (1987). Innovation, market structure, and firm size. The review of Economics and Statistics, 567-574. https://doi.org/10.2307/1935950

Afana, A. and EL Agha, A. (2019). The Role of Organizational Environment in Enhancing Managerial Empowerment in Al-Aqsa Network for Media and Art Production, International Journal of Business Ethics and Governance, 2(2), 30-65. https://doi.org/10.51325/ijbeg.v2i2.40 
Al-Afifi, A. A. M. (2019). Factors Affecting Decision Makers Preference of MSMEs in Financing Sources Choice, International Journal of Business Ethics and Governance, 2(2),16-29. https://doi.org/10.51325/ijbeg.v2i2.31

Alareeni, B. (2019). A Review of Auditors' GCOs, Statistical Prediction Models and Artificial Intelligence Technology, International Journal of Business Ethics and Governance, 2(1),19-31. https://doi.org/10.51325/ijbeg.v2i1.30

Alareeni, B. (2018). Does corporate governance influence earnings management in listed companies in Bahrain Bourse?, Journal of Asia Business Studies, 12(4), 551-570. https://doi.org/10.1108/JABS-06-2017-0082

Alareeni, B.A. (2019). The associations between audit firm attributes and audit qualityspecific indicators: A meta-analysis, Managerial Auditing Journal, 34(1), 6-43. https://doi.org/10.1108/MAJ-05-2017-1559

Aljamal, S. (2018). The Practice of Transformational Management and its Role in Achieving Institutional Excellence from the Point of View of Workers in the Directorates of Education in Hebron, International Journal of Business Ethics and Governance, 1(1), pp. 64-90. https://doi.org/10.51325/ijbeg.v1i1.12

Aminova, M., Jegers, M. (2011). Informal Structures and Governance Processes Transition Economies: The Case of Uzbekistan. International Journal of Public Administration, 34(9):579-590. https://doi.org/10.1080/01900692.2011.588436

Aminova, M., Mareef, S. and Machado, C. (2020). Entrepreneurship Ecosystem in Arab World: the status quo, impediments and the ways forward, International Journal of Business Ethics and Governance, 3(3), 1-13. https://doi.org/10.51325/ijbeg.v3i3.37

Audretsch, D. B. (1995). Innovation, growth and survival. International journal of industrial organization, 13(4), 441-457. https://doi.org/10.1016/0167-7187(95)00499$\underline{8}$

Baregheh, A., Rowley, J., \& Sambrook, S. (2009). Towards a multidisciplinary definition of innovation. Management decision, 47(8), 1323-1339. https://doi.org/10.1108/00251740910984578

Buddelmeyer, H., Jensen, P. H., \& Webster, E. (2009). Innovation and the determinants of company survival. Oxford Economic Papers, 62(2), 261-285. https://doi.org/10.1093/oep/gpp012

Cohen, W. M., Nelson, R. R., \& Walsh, J. P. (2000). Protecting their intellectual assets: Appropriability conditions and why US manufacturing firms patent (or not) (No. w7552). National Bureau of Economic Research. https://doi.org/10.3386/w7552

Colombelli, A., Krafft, J., \& Quatraro, F. (2019). Firms' growth, green gazelles and ecoinnovation: evidence from a sample of European firms. Small Business Economics, 118. https://doi.org/10.1007/s11187-019-00236-8

Damanpour, F. (1992). Organizational size and innovation. Organization studies, 13(3), 375-402. https://doi.org/10.1177/017084069201300304

Freel, M. S. (1999). Where are the skills gaps in innovative small firms?. International journal of entrepreneurial behavior \& research, 5(3), 144-154. https://doi.org/10.1108/13552559910371095

Fryges, H., Gottschalk, S., \& Kohn, K. (2009). The KfW/ZEW start-up panel: design and research potential. ZEW-Centre for European Economic Research Discussion Paper, (09-053). https://doi.org/10.2139/ssrn.1494326

Gottschalk, S. (2013). The Research Data Centre of the Centre for European Economic Research (ZEW-FDZ) (No. 13-051). ZEW Discussion Papers. https://doi.org/10.3790/schm.133.4.607

Hage, J. (1980). Theories of organizations: Form, process, and transformation. New York: Wiley. 
Hyytinen, A., Pajarinen, M., \& Rouvinen, P. (2015). Does innovativeness reduce startup survival rates? Journal of Business Venturing, 30(4), 564-581. https://doi.org/10.1016/j.jbusvent.2014.10.001

Jalonen, H. (2012). The uncertainty of innovation: a systematic review of the literature. Journal of Management Research, 4(1), 1. https://doi.org/10.5296/jmr.v4i1.1039

Kerr, W. R., \& Nanda, R. (2015). Financing innovation. Annual Review of Financial Economics, 7, 445-462. https://doi.org/10.1146/annurev-financial-111914-041825

Kim, W. C., \& Mauborgne, R. (1997). The strategic logic of high growth. Harvard Business Review on Strategies for Growth.

Kirner, E., Kinkel, S., \& Jaeger, A. (2009). Innovation paths and the innovation performance of low-technology firms-An empirical analysis of German industry. Research Policy, 38(3), 447-458. https://doi.org/10.1016/j.respol.2008.10.011

Krishna, A., Agrawal, A., \& Choudhary, A. (2016, December). Predicting the outcome of startups: less failure, more success. In 2016 IEEE 16th International Conference on Data Mining Workshops (ICDMW) (pp. 798-805). IEEE. https://doi.org/10.1109/ICDMW.2016.0118

Leten, B., Landoni, P., \& Van Looy, B. (2014). Science or graduates: How do firms benefit from the proximity of universities?. Research Policy, 43(8), 1398-1412.

https://doi.org/10.1016/j.respol.2014.03.005

Lindgardt, Z., Reeves, M., Stalk, G., \& Deimler, M. S. (2009). Business model innovation. When the Game Gets Tough, Change the Game, The Boston Consulting Group, Boston, MA.

Link, A. N., \& Siegel, D. S. (2005). University-based technology initiatives: Quantitative and qualitative evidence. Research Policy, 34(3), 253-257. https://doi.org/10.1016/j.respol.2005.01.005

Madrid-Guijarro, A., Garcia, D., \& Van Auken, H. (2009). Barriers to innovation among Spanish manufacturing SMEs. Journal of Small Business Management, 47(4), 465488. https://doi.org/10.1111/j.1540-627X.2009.00279.x

Mohamed Hessian, M. I. (2018). The Impact of Managerial Ability on the Relation between Real Earnings Management and Future Firm's Performance: Applied Study, International Journal of Business Ethics and Governance, 1(3), 43-80.

Moroni, I., Arruda, A., \& Araujo, K. (2015). The design and technological innovation: how to understand the growth of startups companies in competitive business environment, Procedia Manufacturing, 3, 2199-2204. https://doi.org/10.1016/j.promfg.2015.07.361

Nanda, R., \& Rhodes-Kropf, M. (2013). Investment cycles and startup innovation. Journal of Financial Economics, 110(2), 403-418. https://doi.org/10.1016/j.jfineco.2013.07.001

Nanda, R., \& Rhodes-Kropf, M. (2016). Financing risk and innovation. Management Science, 63(4), 901-918. https://doi.org/10.1287/mnsc.2015.2350

Patel N. (2015). $90 \%$ of startups fail: here's what you need to know about the $10 \%$. Forbes. https://doi.org/10.1097/01.NME.0000457290.69959.78

Pridham D. (2018). entrepreneurs: here's good news for 2018. Forbes.

Salman, M. and Battour, M. (2020). Career Excellence between Leadership Roles and Achievement Motivation for Employees in the Ministry of Education in the United Arab Emirates, International Journal of Business Ethics and Governance, 3(1), 46-96. doi: 10.51325/ijbeg.v3i1.33. https://doi.org/10.51325/ijbeg.v3i1.33

Stock, G. N., Greis, N. P., \& Fischer, W. A. (2002). Firm size and dynamic technological innovation. Technovation, 22(9), 537-549. https://doi.org/10.1016/S0166$\underline{4972(01) 00061-X}$ 
Thornhill, S. (2006). Knowledge, innovation and firm performance in high-and lowtechnology regimes. Journal of business venturing, 21(5), 687-703. https://doi.org/10.1016/j.jbusvent.2005.06.001

Wagner, S. M. (2008). Innovation management in the German transportation industry. Journal of Business Logistics, 29(2), 215-231. https://doi.org/10.1002/j.21581592.2008.tb00093.x

Wood, E. (1997). SME innovator types and their determinants. ESRC Centre for Business Research, University of Cambridge. 